\title{
Physicians support assisted death for mature minors, but not mental illness
}

\author{
— Cite as: CMAJ 2017 September 11;189:E1173. doi: 10.1503/cmaj.1095491
}

Posted on cmajnews.com on Aug. 23, 2017.

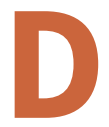

octors attending a session on medical aid in dying at the Canadian Medical Association (CMA) General Council supported the use of advance directives and allowing mature minors to access assisted death. However, they split on opening up the service to otherwise healthy people with mental illness.

In a poll of those attending the session, $83 \%$ said they would support the use of advance directives to request medical aid in dying in cases where a person was otherwise unable to give consent. Some $69 \%$ would support opening the service to "mature minors," including cases in which a guardian might request assisted death for a terminally ill infant, for example. However, after roundtable discussions, less than half (46\%) of doctors polled said they would support assisted death on the basis of mental illness alone.

Medical aid in dying has been legal for almost a year in Canada, but debate over access to the service continues. Currently, eligibility for assisted death is restricted to adults experiencing intolerable suffering from a serious and incurable condition, so long as they are able to consent to the procedure and their natural death is reasonably foreseeable. There are challenges before the courts to expand these criteria and the federal government is reviewing the evidence when it comes to advance directives, mature minors and mental illness.

Assisted death continues to be a divisive issue for physicians, said Dr. Jeff Blackmer, vice-president of medical professionalism at CMA. "One thing we've learned from other jurisdictions is this conversation will never end. Once that Pandora's Box has been opened, this is something we will continue to debate."

Even the current rules are sometimes difficult to apply, said Blackmer. For

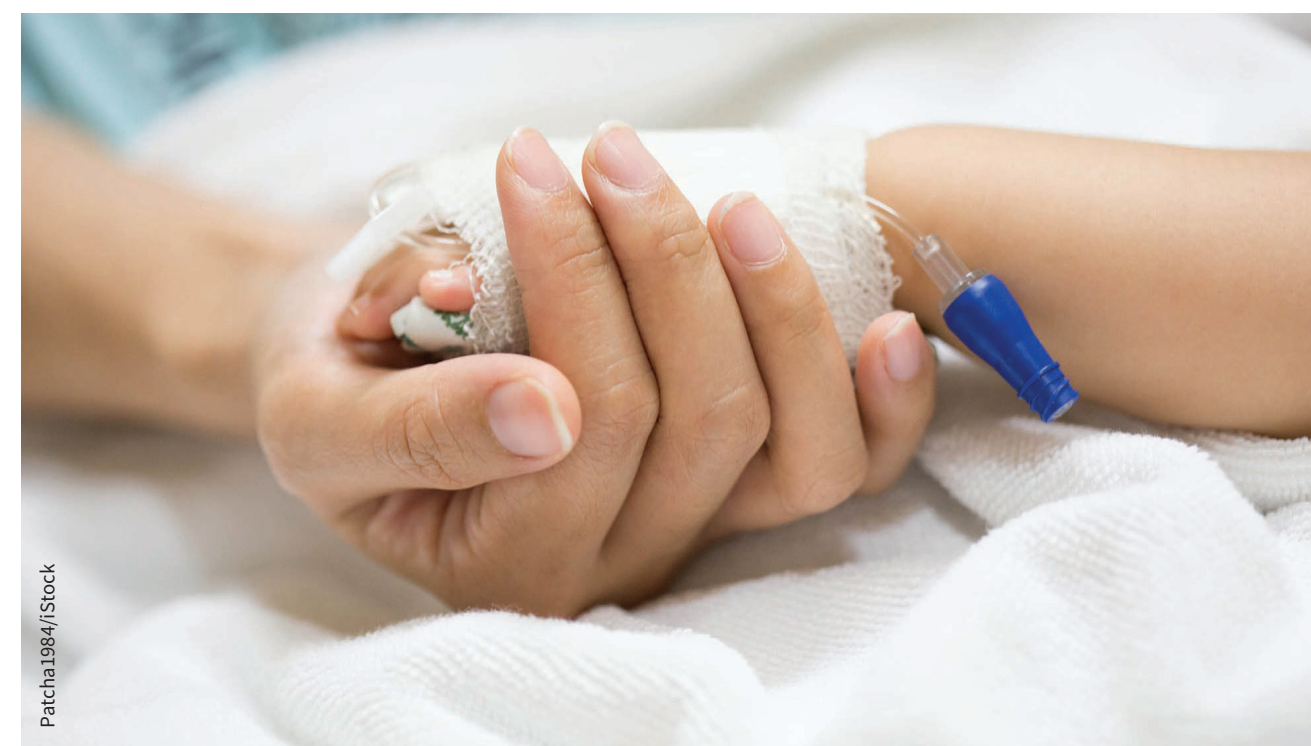

Doctors at CMA General Council weighed in on expanding eligibility for medical aid in dying.

example, there are still "grey zones" when it comes to judging whether a person's death is foreseeable, he said. "It may be left up to the courts to decide."

At least 970 Canadians received medical aid in dying last year, accounting for just $0.6 \%$ of deaths, according to federal estimates. Most had cancer and died in hospital. There were equal proportions of men and women who received the service; their average age was 72 .

More Canadians will likely opt for assisted death "as the public gets more comfortable with this idea," said Blackmer. For example, $3.75 \%$ of deaths in the Netherlands and $1.83 \%$ of deaths in Belgium were assisted in 2015. "Those jurisdictions started out lower and gradually increased over time," particularly as they opened the service to more of the population.

It's still difficult to get an accurate picture of assisted deaths in Canada, Blackmer added. "Part of the challenge we have is there's no federal data collection system," he said. "Each province has their own data set and some are very reluctant to report because they have small numbers and are worried about privacy concerns."

The Canadian Institute for Health Information is working on a way to collect this data nationally. "CMA is involved to make sure the data they collect is clinically relevant and it doesn't become onerous on providers because we're already hearing about excessive paperwork," Blackmer said.

Ultimately, debate over assisted death is just a "small part of the larger discussion on end-of-life issues," he said. "We need to continue to advocate for the other $99 \%$ of patients who need our help and support in facilitating end-of-life conversations and in making sure they have access to high quality palliative and end-of-life care."

Lauren Vogel, CMAJ 